\title{
Assessment of Breast Feeding Practices among Mothers of Cleft Lip and Palate Babies
}

\author{
Pravisha Pandey ${ }^{1}$, Mukta Singh ${ }^{2}$ \\ ${ }^{1}$ Research Scholar, SHIATS, Allahabad, U.P., India \\ ${ }^{2}$ Assistant professor, BHU, Varanasi, U.P., India
}

\begin{abstract}
Introduction: The goal in feeding an infant with a cleft lip or palate is similar to the goals in feeding any infant, maintaining nutrition in the first priority. The feeding difficulties in babies with cleft lip and/or palate are well documented; as many as 63\% of them experience such difficulties; most of these are related to reduce sucking efficiency. Thus, the present study was designed to find out the knowledge, attitude, beliefs and feeding methods practiced by the parents of babies with cleft lip and palate. Materials and method: Sample of 200 respondents was recruited as part of simple random sampling, in age group between 18 to 35 years. Study site was the G.S.Memorial hospital, Mahmoorganj, Varanasi. Primary tool used in the study were pre designed and pre tested questionnaire which consisted of general and specific information required for the study. Face to face personal interview methods were employed to collect the data. Results: The level of education among the women was categorized as primary, secondary, intermediate, graduate and illiterate also with 10\%, $25 \%, 5 \%, 20 \%$ \& $40 \%$ respectively. In this study ratio of $62 \%$ children received colostrum while $38 \%$ did not receive colostrum due to several reasons like myths, lack of sucking reflex etc. Whereas only $2 \%$ mothers know the importance of colostrum and 98\% mothers have no knowledge regarding importance of colostrum. According to this study first breast milk was secreted in 30\% mothers just after delivery, 25\% mothers' secreted first milk after 5-22 hrs., while 45\% mothers secreted breast milk after 23-72 hrs. The study found that $40 \%$ infants were able to suck, while $30 \%$ had no ability to suck the breast milk, $10 \%$ had partial ability to suck the breast milk, whereas $20 \%$ mothers had to pump their breast to feed their babies. Conclusion: In the present study, spoon feeding was found to be the most common feeding method practiced by parents of children with cleft lip and palate. Prior to birth of their children, majority of mothers were motivated to breastfeed their child, but no attempt was made to enforce one particular method of feeding. The parents were encouraged to find the methods which best suited their baby by a process of trial and error.
\end{abstract}

Keywords: Cleft lip and palate, Infants, Breastfeeding, Methods of feeding, Nutrition

\section{Introduction}

As the years pass, science teaches us more about the purpose of the thousands of unique components in human milk and the importance of the act of breastfeeding to mothers and babies. But human milk and breastfeeding may be even more important when a baby is born with special needs. Although babies with cleft defects need human milk as much or more than other babies, they also face breastfeeding challenges. With a cleft lip, most babies can breastfeed with some extra help. When a baby is born with a cleft palate, however, he may face major feeding difficulties, whether fed by breast, bottle, or both. The degree of difficulty will depend upon the severity and location of the cleft, as well as other factors.

A cleft (or opening) of the lip and/or palate is one of the most common birth defects, occurring in the US in 1 of every 700 births. These two conditions may occur together or separately. One-third of these babies have a cleft lip only, one-third has a cleft palate only, and one-third has both conditions. A cleft of the lip occurs when parts of the baby's upper lip do not fuse together as the baby is developing in utero. A cleft palate occurs when parts of the baby's palate do not fuse. The baby may have a cleft of the soft palate (the roof of the rear of the mouth comprised of soft muscle covered with mucous membrane) or both the soft and hard palates. The muscles of the soft palate are used for swallowing, so a large cleft of the soft palate can have a major effect on the baby's ability to feed. Some babies have what's called a "sub mucosal cleft," an opening of muscle or bone beneath the intact skin that is invisible to the eye. A sub mucosal cleft may not affect feedings, because unlike a baby with other types of cleft palate, the baby is able to seal off the mouth and generate suction.

With a cleft lip, depending on the type and location of the cleft, some mothers find that breastfeeding poses few problems for them or their babies even before corrective surgery. With a cleft palate, feedings - whether by breast, bottle, or both - usually present challenges before corrective surgery. For many babies with a cleft palate, feeding exclusively at the breast may be impossible until the palate is surgically repaired. In this case, a mother can provide her milk for her baby by expressing her milk and feeding it to the baby with special feeding devices. Mother and baby may also enjoy spending time with baby at the breast, even if the baby is unable to get a full feeding there. Even though pumping and supplementing can be challenging, research indicates that babies enjoy optimal health when they receive mother's milk.

Objective

- To investigate the breast feeding practices among mothers of cleft lip \& palate babies.

- To assess the knowledge of mothers regarding benefits of breast feeding \& exclusive breast feeding.

- To know about difficulties related to breast feeding.

\section{Methods and Material}

The main method consisted of the following steps.

- Selection of locale: - G.S. Memorial Hospital, Mahmoorganj, Varanasi.U.P.,India 


\section{International Journal of Science and Research (IJSR) \\ ISSN (Online): 2319-7064 \\ Index Copernicus Value (2013): 6.14 | Impact Factor (2015): 6.391}

- Type of study: - The type of study was purposive with the aim of assessment of breast feeding practices among mothers of cleft lip \& palate babies.

- Sample selection: - The only criteria for selection of the subjects were women should be lactating. Subjects were randomly selected for the purpose of study.

- Sample Size: - This study was conducted on 100 lactating women, aged 18 to 35 years.

- Period of study: - Present study was conducted from August 2011 to February 2012.

- Tools of Study: - Primary tool used in the study was pre designed and pre tested questionnaire which consisted of general and specific in-formations required for the study.

- General Information: - This section consisted of general questions such as name of the subject, age of mothers \& age of child, occupation of mothers, Education, family income per month etc.

- Specific Information: - This section consisted information about knowledge exclusive breast feeding, their attitude, beliefs regarding breast feeding practices.

- Analysis and Tabulation of the Data: - On the basis of the data collected, a comprehensive master chart was prepared. The findings have been presented in the form of tables. Tabulation of data was done to make comparison of each attribute studied. Certain statistical method like: percentage and graphical representation was used.

\section{Results}

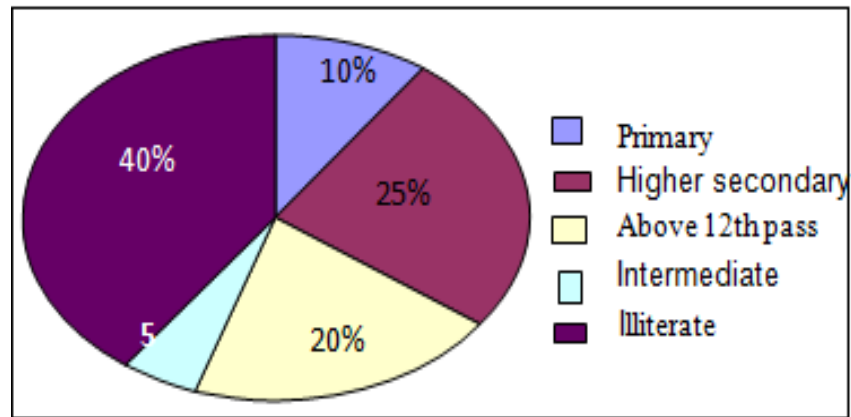

Figure 1: Distribution of respondents according to their educational level

Above graph shows that majority of $40 \%$ respondents were illiterate, $10 \%$ were educated up to primary education level, $25 \%$ had educated till secondary level, and 5\% were educated up to intermediate level while $20 \%$ had more than $12^{\text {th }}$ class.

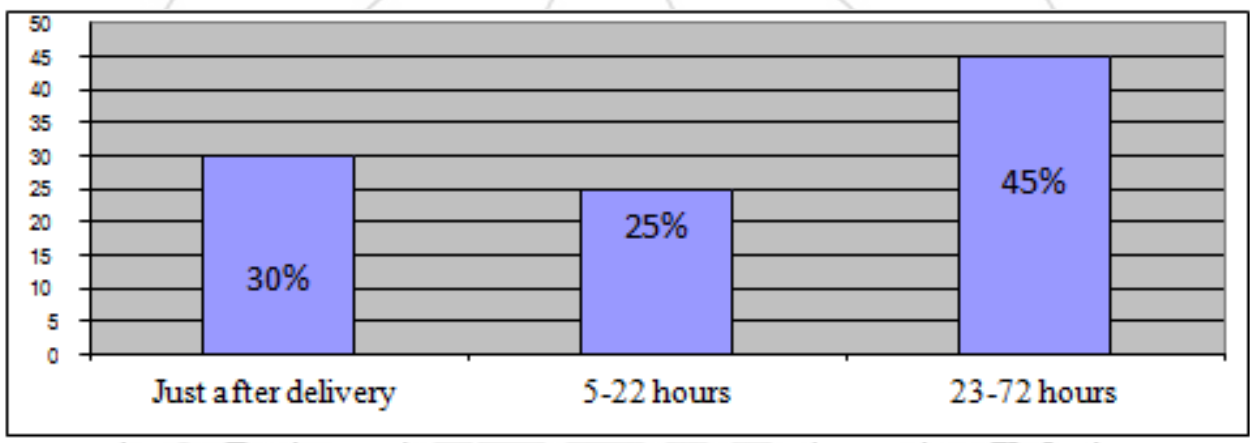

Figure 2: Distribution of respondents according to their time of secretion of first milk

Above graph shows that $30 \%$ mothers secreted breast milk just after the delivery, $25 \%$ mothers secreted first milk after 5-22 hours while $45 \%$ mothers secreted breast milk after 23-72 hours.

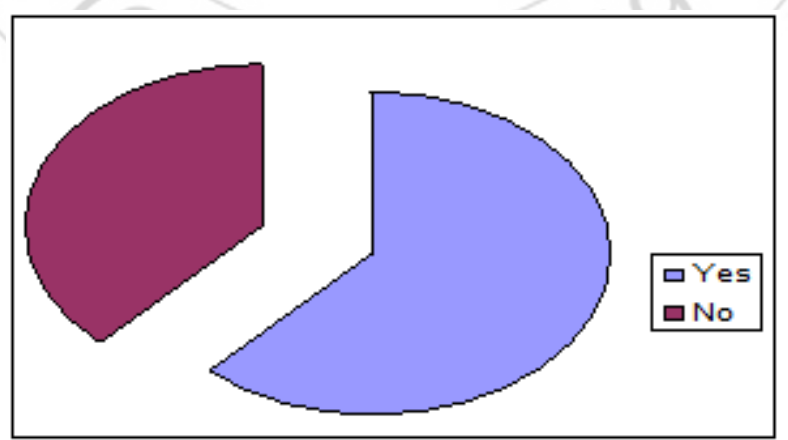

Figure 3: Distribution of children who received colostrum

Above graph shows that $62 \%$ children received colostrum, while $38 \%$ child did not receive colostrum. 
International Journal of Science and Research (IJSR)

ISSN (Online): 2319-7064

Index Copernicus Value (2013): 6.14 | Impact Factor (2015): 6.391

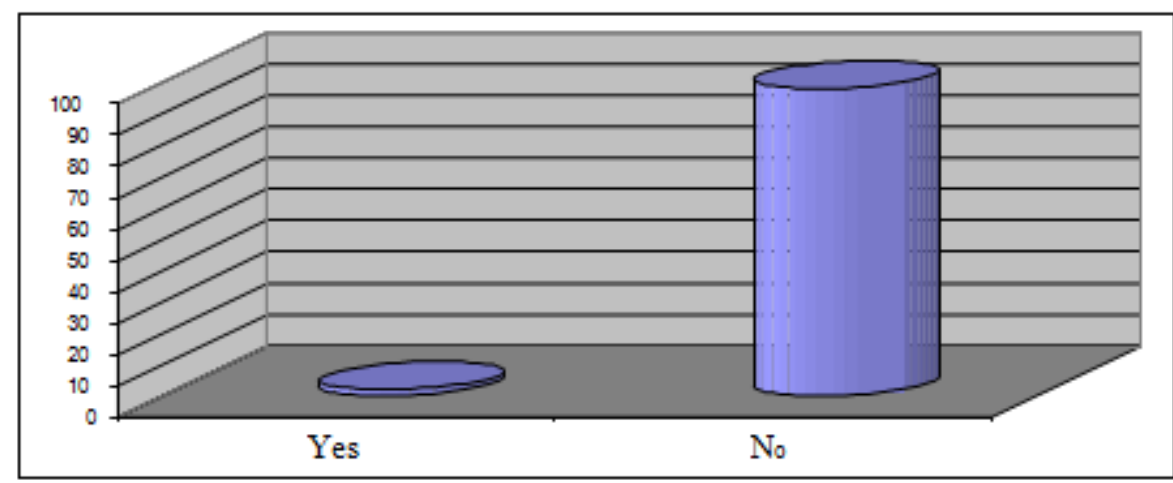

Figure 4: Distribution of respondents according to their knowledge regarding importance of colostrums

Above graph shows that only $2 \%$ respondents have knowledge, $98 \%$ respondents have no knowledge regarding importance of colostrum.

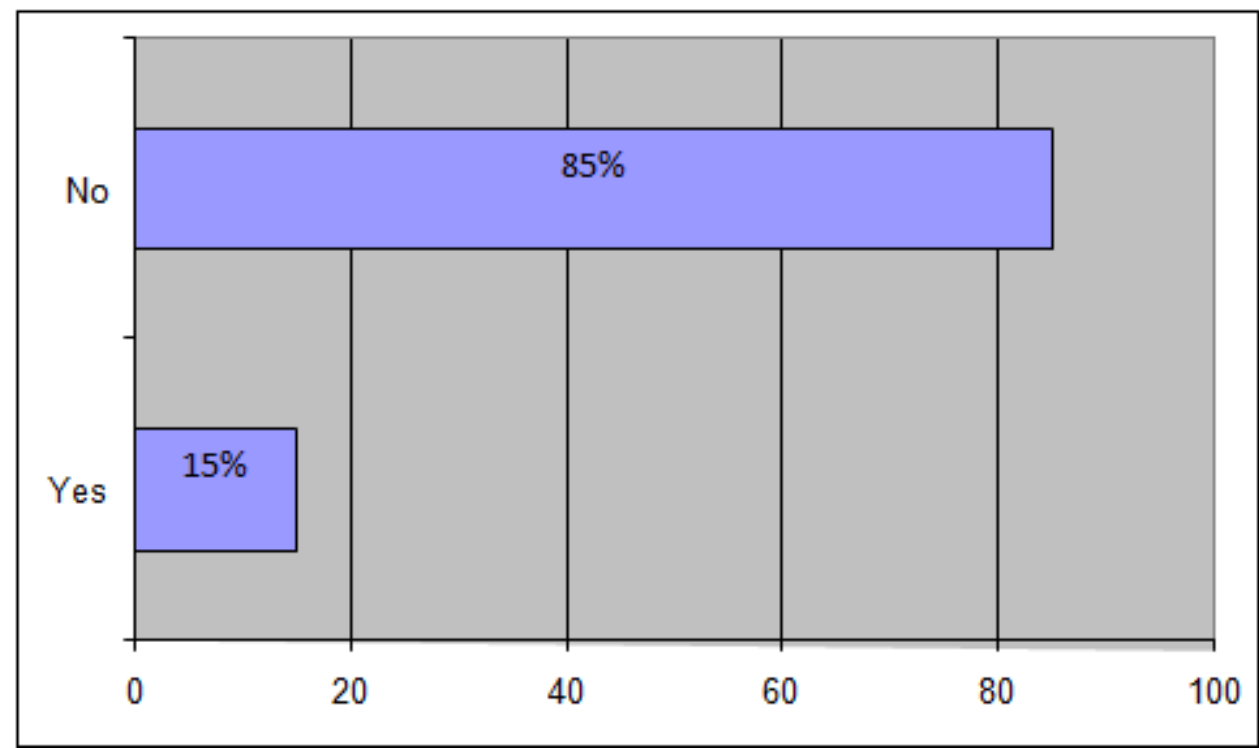

Figure 5: Distribution of babies on the basis of taking exclusive breast feeding

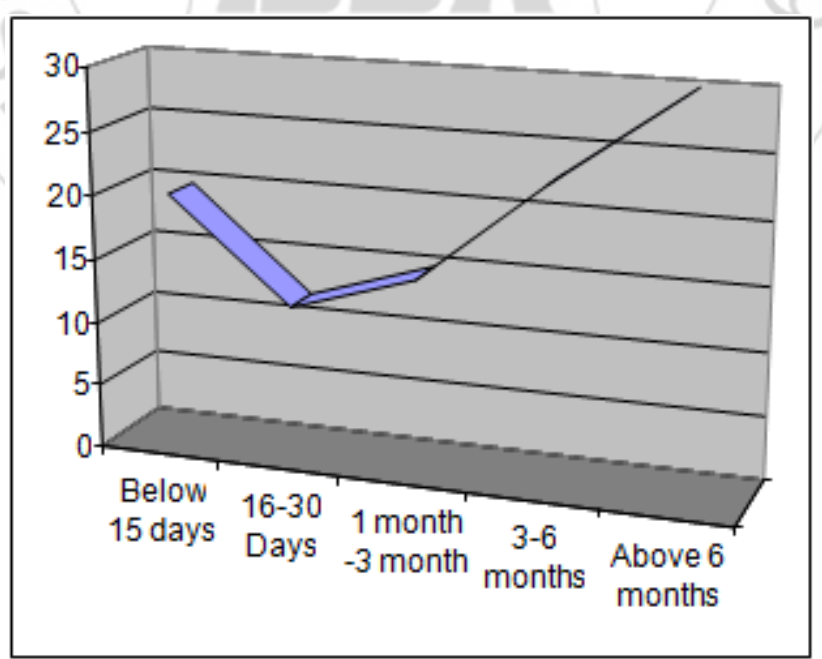

Figure 6: Distribution of respondents on the basis of duration of breast feeding.

Above figure shows that $20 \%$ mothers fed their children below 15 days, $12 \%$ mothers fed their babies up to 1 month, $15 \%$ fed their babies up to 3 month, and 23\% mothers fed their babies up to 6 months, while $30 \%$ mothers fed their babies more than 6 months. 
International Journal of Science and Research (IJSR)

ISSN (Online): 2319-7064

Index Copernicus Value (2013): 6.14 | Impact Factor (2015): 6.391

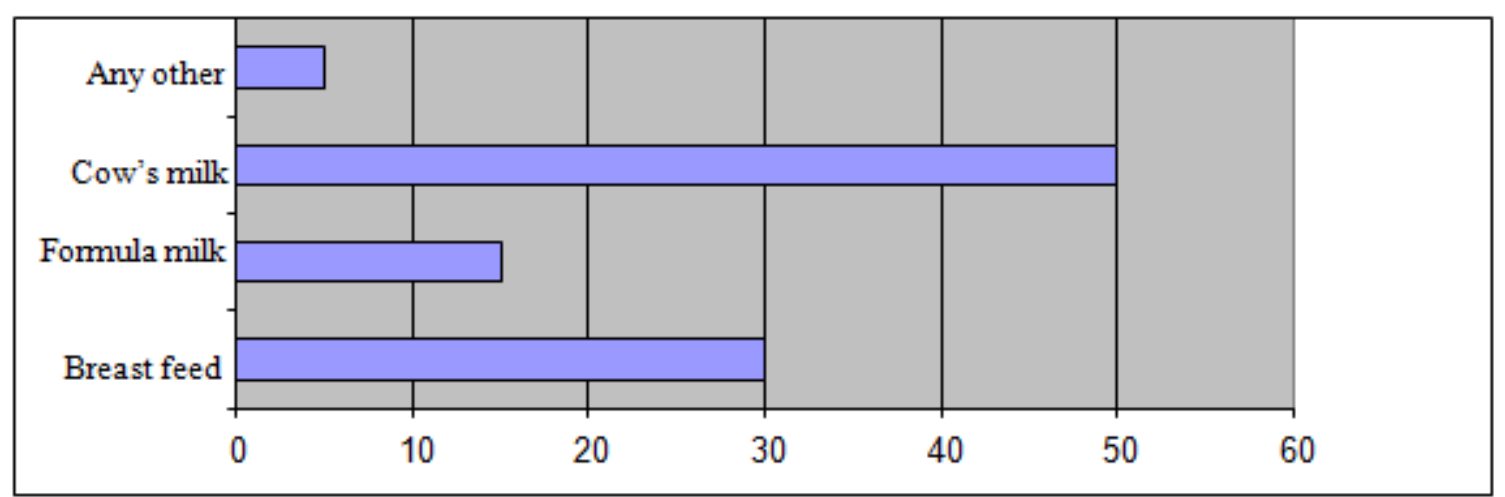

Figure 7: Distribution of children according to their first feed given by their mothers

Above graph shows that $30 \%$ children took first feed as breast milk , $15 \%$ took formula milk , $50 \%$ took cow's milk, while $5 \%$ children took any other product as first feed.

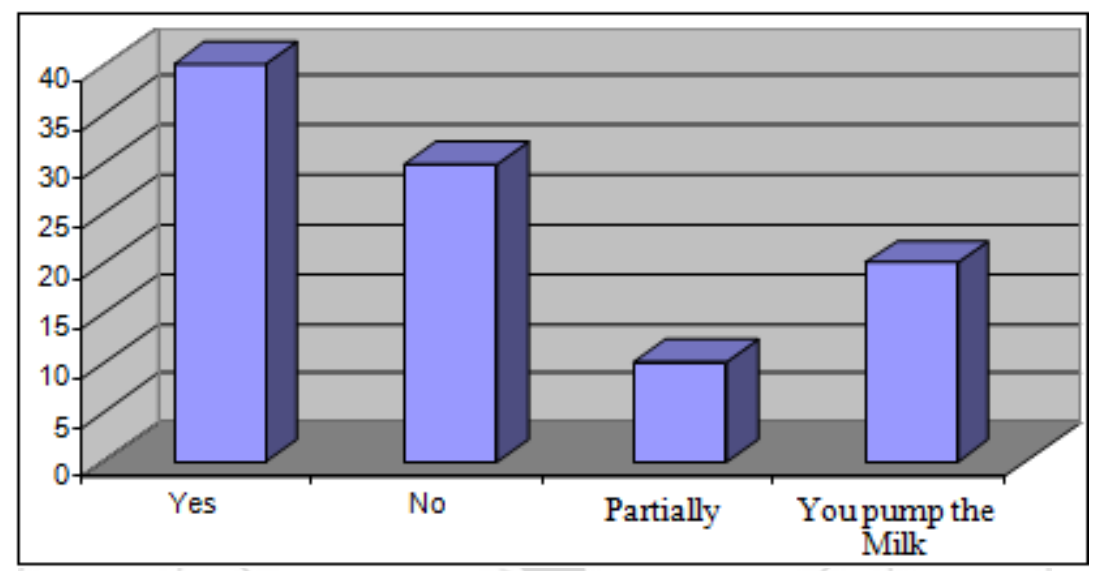

Figure 8: Distribution of children according to their sucking ability

Above graph shows that $40 \%$ children had sucking ability, $30 \%$ had no ability to sucking the breast milk, $10 \%$ had partial ability to suck the breast milk, and $20 \%$ mothers pumped their breast to feed the baby.

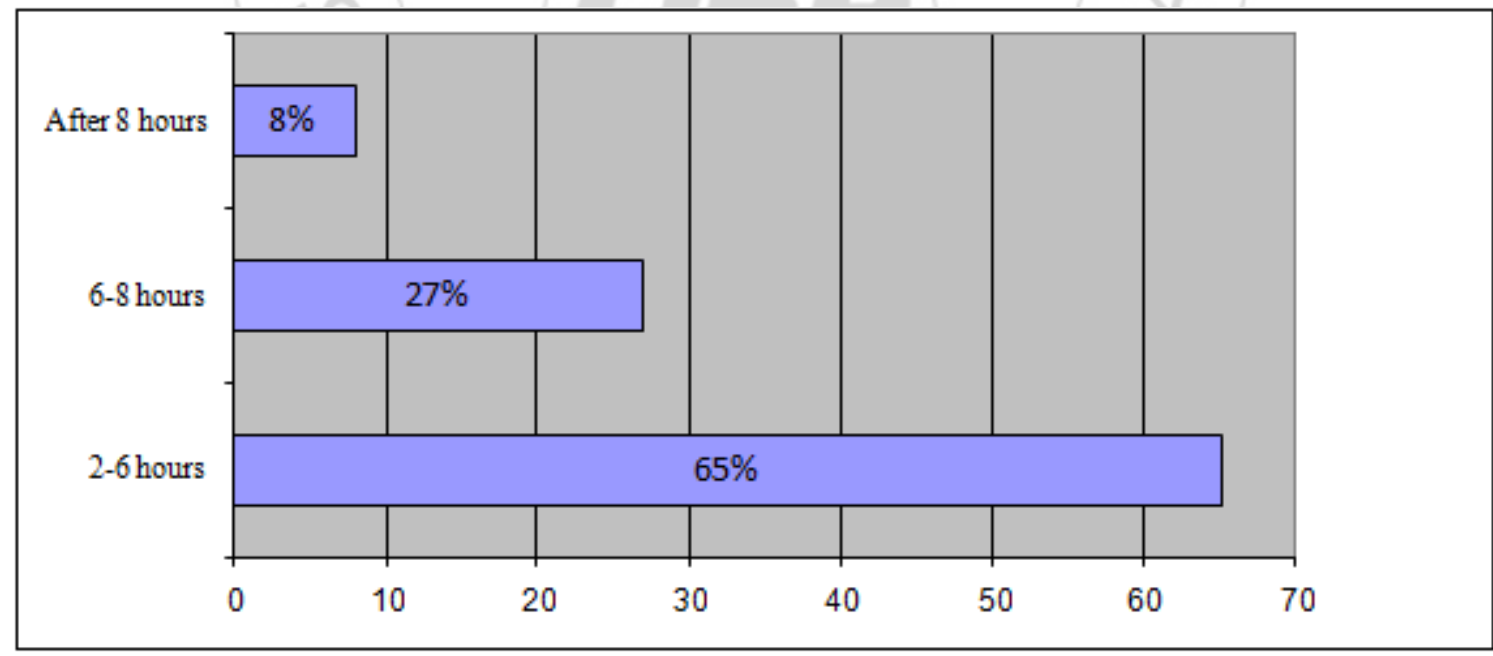

Figure 9: Distribution of respondents on the basis of interval of breast feeding

Above graph shows that $65 \%$ mothers fed their baby within 2-6 hours, $27 \%$ mothers fed their babies after 6-8 hours in a day, while $8 \%$ mothers fed their babies after 8 hours in a day. 
International Journal of Science and Research (IJSR)

ISSN (Online): 2319-7064

Index Copernicus Value (2013): 6.14 | Impact Factor (2015): 6.391

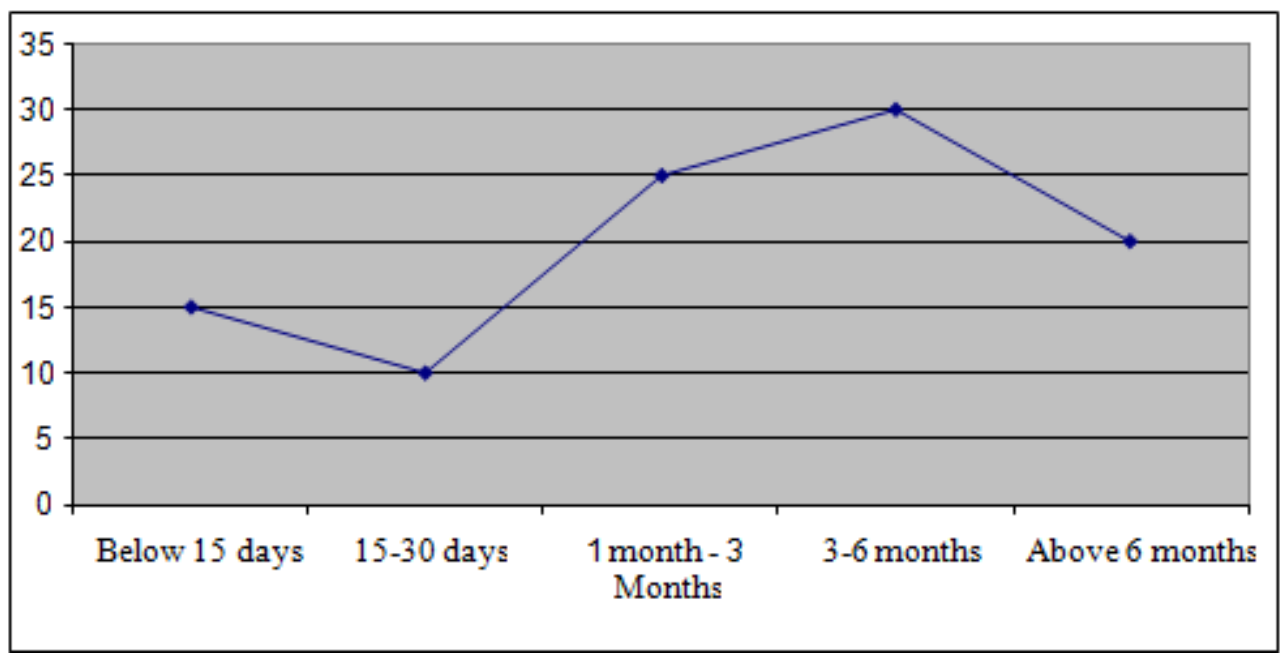

Figure 10: Distribution of respondents on the basis of sufficient milk secretion.

Above graph shows that $15 \%$ had sufficient milk secretion up to 15 days, $10 \%$ had up to 30 days, $25 \%$ had up to 3 months and $30 \%$ had up to 6 months, while $20 \%$ mothers had sufficient milk above 6 months.

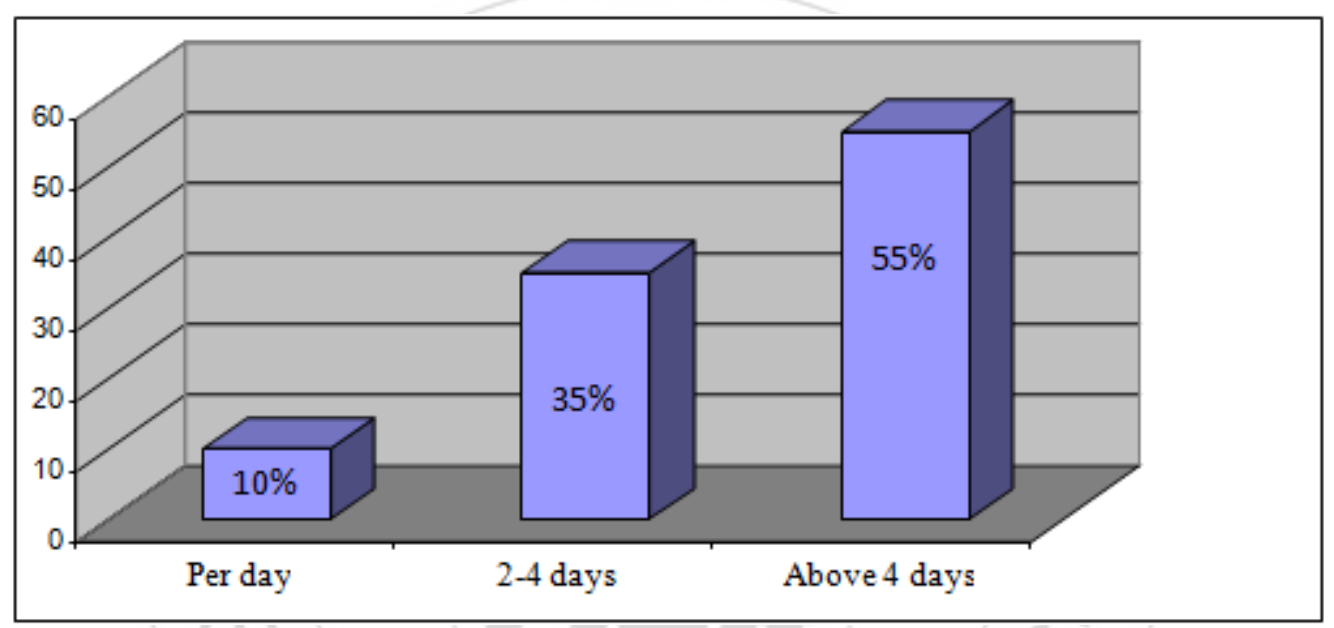

Figure 11: Distribution of respondents who sterilize the bottle after feeding

Above graph shows that $10 \%$ mothers were sterilize the bottle per day, $35 \%$ mothers sterilized the feeding bottle within 2-4 days, while 55\% mothers sterilized the bottle more than 4 days.

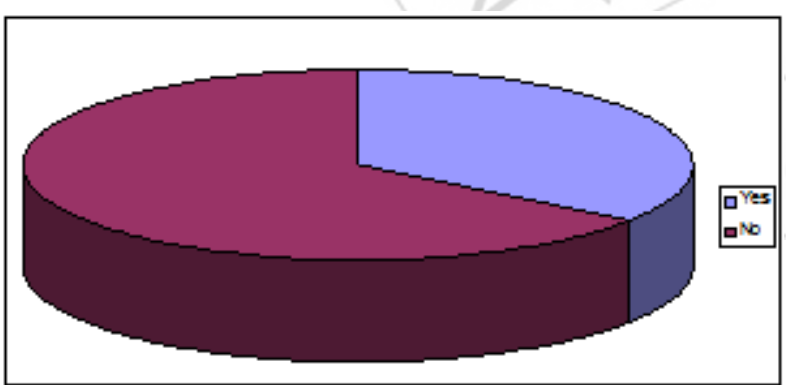

Figure 12: Distribution of respondents who avoid breastfeeding outside the home

Above graph shows that $35 \%$ respondents avoided the breastfeeding outside the home, while $65 \%$ respondents did not avoid the breast feeding outside the home.

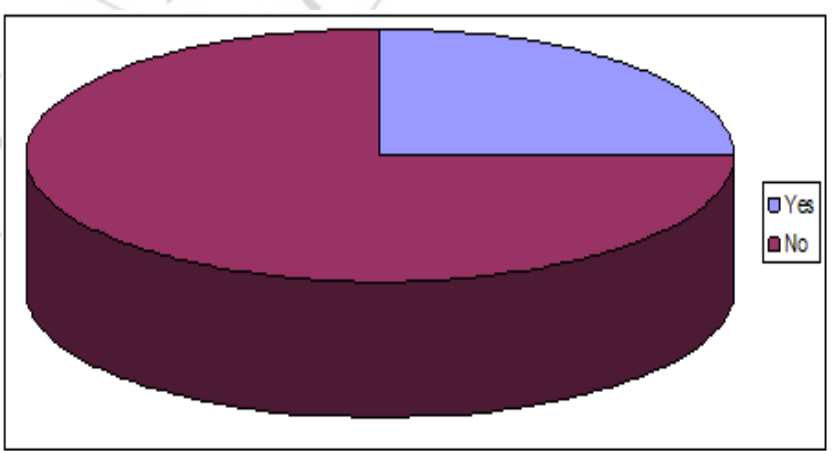

Figure 13: Distribution of respondents on the basis of knowing about supplementary foods available in the market.

Above shows that $25 \%$ respondents have the knowledge regarding the supplementary food which is available in the market, while $75 \%$ mothers have no knowledge regarding supplementary food. 


\section{International Journal of Science and Research (IJSR) \\ ISSN (Online): 2319-7064}

Index Copernicus Value (2013): 6.14 | Impact Factor (2015): 6.391

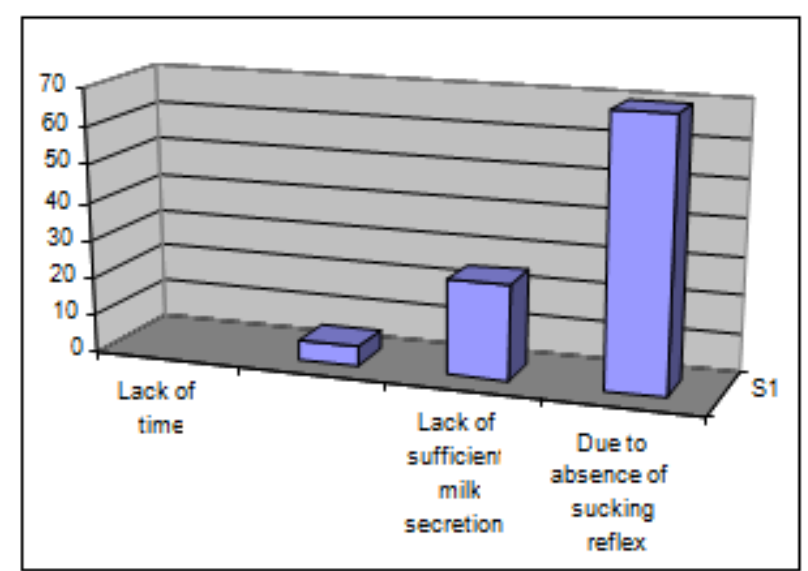

Figure 14: Factors responsible for stopping breast feeding.

Above graph shows that 5\% mothers stopped the breastfeeding due to lack of time, $25 \%$ mothers stopped the breastfeeding due to lack of sufficient milk secretion, while $70 \%$ mothers had stopped breastfeeding due to absence of sucking reflex.

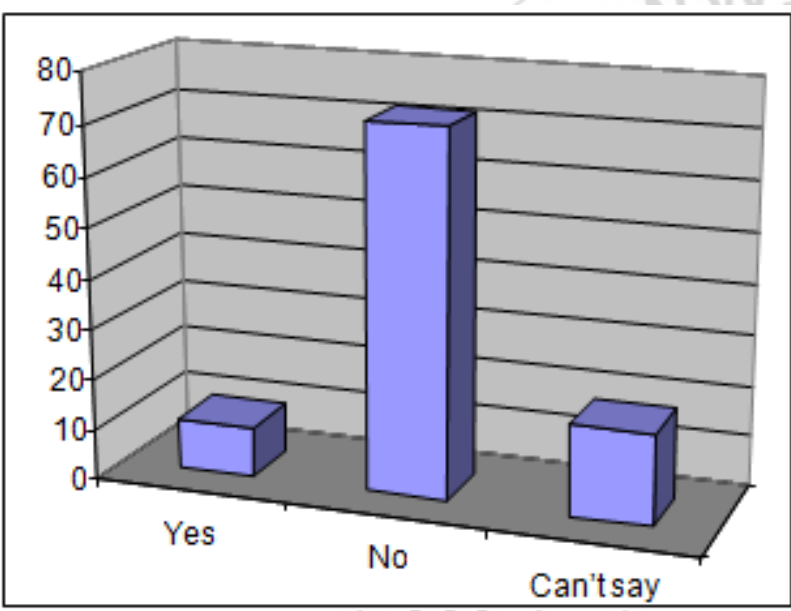

Figure 15: Distribution of respondents on the basis of thinking that the infant formula contains all ingredients found in breast milk
Above graph shows that $25 \%$ respondents have the knowledge regarding the supplementary food which is available in the market, while $75 \%$ mothers have no knowledge regarding supplementary food.

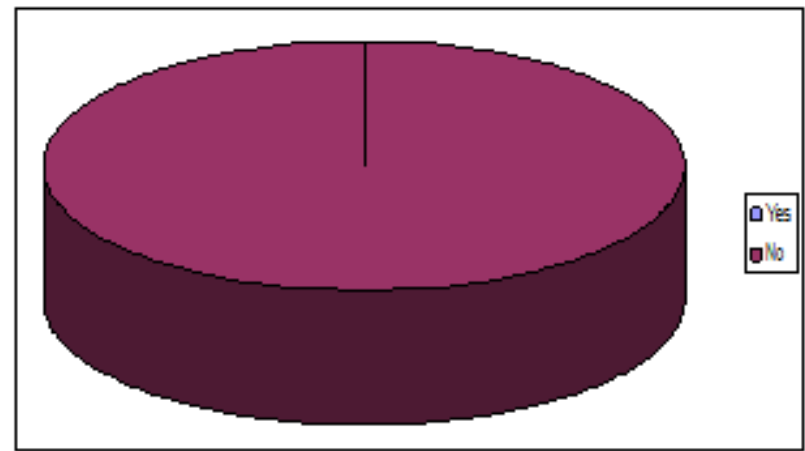

Figure 16: Distribution of respondents on the basis of awareness regarding any aid beneficial in breastfeeding

Above graph shows that $10 \%$ respondents said yes. $72 \%$ said no, while $18 \%$ respondents said can't say.

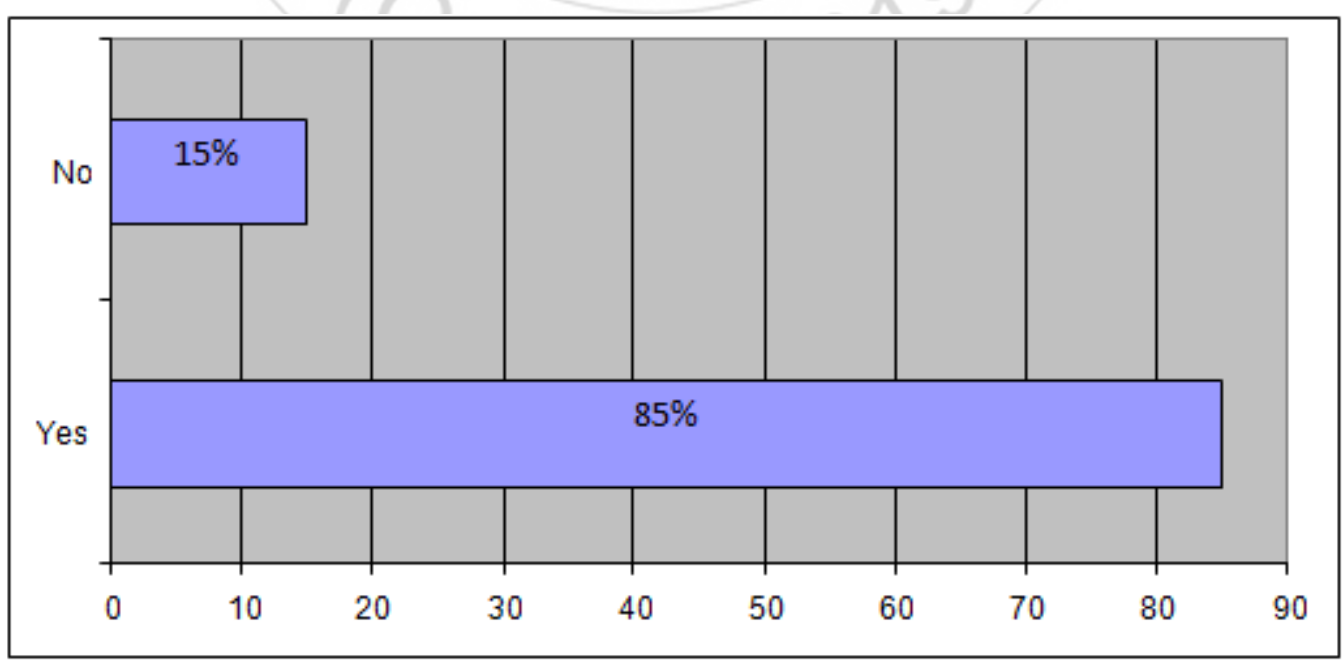

Figure 17: Distribution of respondents who have sufficient time for breast feeding

Above graph shows that $85 \%$ respondents had sufficient time for breastfeed, $15 \%$ had no sufficient time to breast feed. 


\section{International Journal of Science and Research (IJSR) \\ ISSN (Online): 2319-7064}

Index Copernicus Value (2013): 6.14 | Impact Factor (2015): 6.391

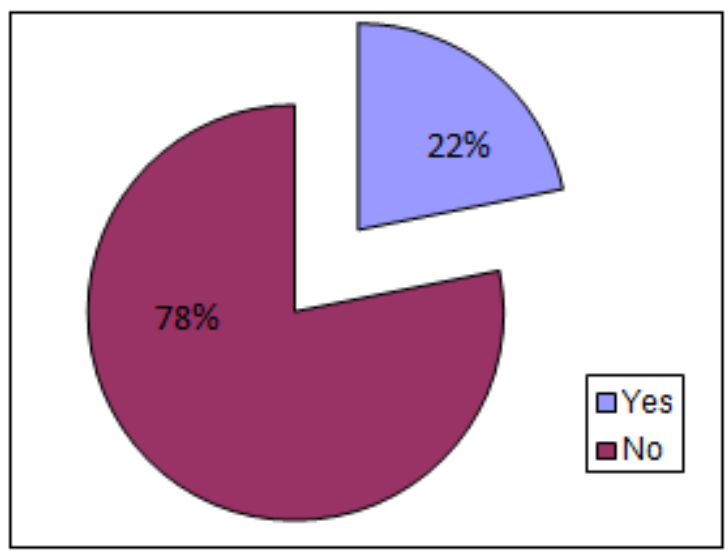

Figure 18: Distribution of respondents who know about any programs related to maternal health and child care.

Above graphshow that $22 \%$ respondents have knowledge, while $78 \%$ have no any knowledge regarding any programs regarding maternal health $\&$ child care.

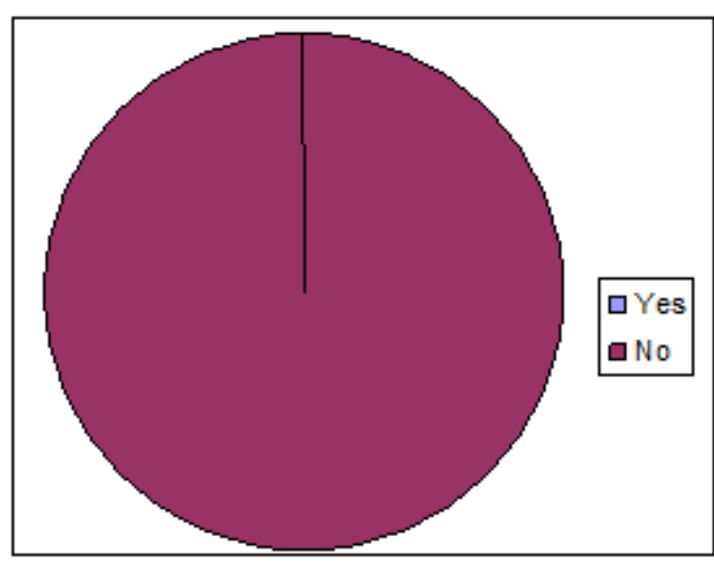

Figure 19: Distribution of respondents who received any supplementary food given by aganwadi worker

Above graph shows that $100 \%$ people did not receive any supplementary food given by aganwadi.

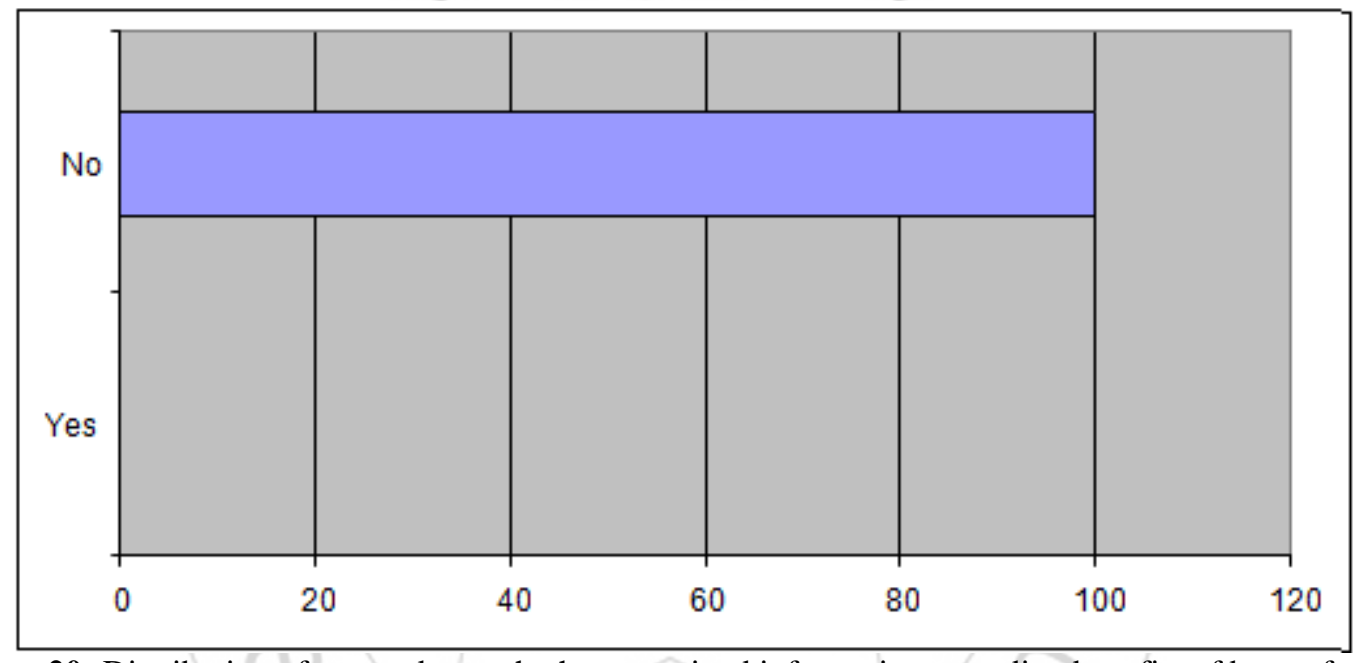

Figure 20: Distribution of respondents who have received information regarding benefits of breast feeding

Above graph shows that $100 \%$ did not receive any information regarding the benefits of breastfeeding

\section{Summary \& Conclusion}

This study was conducted to assess the percentage of population having knowledge regarding benefits of breast feeding, exclusive breastfeeding \& ratio of mothers practing it. In our community breast feeding have traditional values and certain myths like colostrum are not good for baby. It is generally believed that breast feeding directly promotes overall health of the child and results in decreased childhood morbidity and mortality. In this study a total no. 100 mothers were recruited, where the age ranges was between $18-35$ years and mean age was 25 years.

The level of education among the women was categorized as primary, higher secondary, intermediate, above $12^{\text {th }}$ and illiterate also with $10 \%, 25 \%, 5 \%, 20 \%$ \& $40 \%$ respectively.

It was found that large no. of women was illiterate as it may be because they belong from rural areas. In this study ratio of $62 \%$ children received colostrum while $38 \%$ did not receive colostrum due to several reasons like myths, $30 \%$ lack of sucking reflex etc. Whereas only $2 \%$ mothers know the importance of colostrum and $98 \%$ mothers have no knowledge regarding importance of colostrum.

According to this study first breast milk was secreted in $30 \%$ mothers just after delivery, $25 \%$ mothers' secreted first milk after 5-22 hrs. While $45 \%$ mothers secreted breast milk after 23-72 hrs.

It shows that breast feeding was practice by $20 \%$ mothers within 15 days, $12 \%$ mothers fed their babies up to 1 month, $15 \%$ fed their babies up to 3 months, and $23 \%$ mothers fed their babies up to 6 months, while 30\% mothers fed their babies more than 6 months. The reason may be that $40 \%$ were able to suck, while $30 \%$ had no ability to suck the breast milk, $10 \%$ had partial ability to suck the breast milk ,whereas $20 \%$ mothers had to pump their breast to feed their babies.

If time is considered the findings has been showing that $65 \%$ mothers fed their babies within 2-6 hrs, $27 \%$ fed their babies after 6-8 hrs while $8 \%$ mothers fed their babies after interval of $8 \mathrm{hrs}$. In a day due to several reason like insufficient milk secretion, lack of time. The knowledge regarding 


\section{International Journal of Science and Research (IJSR) \\ ISSN (Online): 2319-7064 \\ Index Copernicus Value (2013): 6.14 | Impact Factor (2015): 6.391}

supplementary foods was minimum means $25 \%$ only, whereas $75 \%$ mothers have no knowledge about them. Thus the growth \& development may be declined if they do not taking sufficient breast milk. The factors responsible for stopping the breastfeeding are 5\% due to lack of sufficient milk secretion \& $70 \%$ had stopped breast feeding due to absence of sucking reflex. In terms of infant formula milk, $10 \%$ mothers think that it is similar to breast, $72 \%$ mothers were not agreed, whereas $18 \%$ were confused either it is similar or not. Some nursing devices are available in the market which may be beneficial for cleft lip \& cleft palate babies but here no respondents had any awareness regarding nursing devices.

\section{References}

[1] Amstalden-M L, Magna, L. A., \& Gil-da-Silva-Lopes. L. (2007). Neonatal care of infants with cleft lip and/or palate: Feeding orientation and evolution of weight gain in a no specialized Brazilian hospital. Cleft PalateCraniofacial Journal, 44, 329-334

[2] Bushra f, Ahmad N, Hussain T, Manan F, Effect of infant feeding practices on birth interval and morbidity among children in North West Province of Pakistan. Journal of Islamic academy of science 1995; 8:69-72.

[3] Chezem, J., C. Friesen, and J. Boettcher, Breastfeeding knowledge, breastfeeding confidence, and infant feeding plans: effects on actual feeding practices. JOGNN: Journal of Obstetric, Gynecologic, \& Neonatal Nursing, 2003. 32(1): p. 40-47.

[4] Clarren, S., Anderson, B., \& Wolf, L. (1987). Feeding infants with cleft lip andcleft palate, cleft palate journal, 24,244-249.

[5] Clarren, S., Anderson, B., \& Wolf, L. (1987). Feeding infants with cleft lip, cleft palate, cleft palate journal, and 24,244-249.

[6] Craniofacial Journal, 40, 84-87. Dalben, G. D., Costa, B., Ribeiro-Gomide, M., \& Teixeira das Neves, L. (2003). Breast-feeding and sugar intake in babies with cleft lip and palate.

[7] Danner SC. Breast feeding the infants with a cleft defect.NAACOGS Clin Issu Perinat Womens Health, Nurs 1992; 3: 634-9.

[8] Dennis, C., et al., The effect of peer support on breastfeeding duration among primiparous women: a randomized controlled trial. Canadian Medical Association Journal, 2002. 166(1): p. 21-28.

[9] Donath, S. and L.H. Amir, Rates of breastfeeding in Australia by state and socioeconomic status: evidence from the 1995 National Health Survey. Breastfeeding Review, 2000. 8(3): p. 23-7.

[10] Kulkarni RN, Ajenaya s, Gujar R.Breast feeding practices in an urban community of Kalamboli, Navi Mumbai. Indian journal of community medicine 2004;

[11] Lande, B., et al., Infant feeding practices and associated factors in the first six months of life: the Norwegian infant nutrition survey. Acta Paediatrica, 2003. 92(2): p. 152-61.

[12] Mizuno, K. (2002). Feeding behaviors of infants with cleft lip and palate. Acta Paediatr, 91, 1227-1232. Reid, J. (2004). A review of feeding intervention for infants with cleft palate. Cleft Palate-CraniofacialJournal, 31, 268-278.
[13] National Health and Medical Research Council, Dietary Guidelines for Children and Adolescents in Australia incorporating the Infant Feeding Guideline for Health Workers. 2003, Canberra: Commonwealth of Australia.

[14] Pincombe, J., et al., Baby Friendly Hospital Initiative (BFHI) Practices and breastfeeding duration in first time mothers in an Adelaide teaching maternity hospital, Australia. in press, 2006.

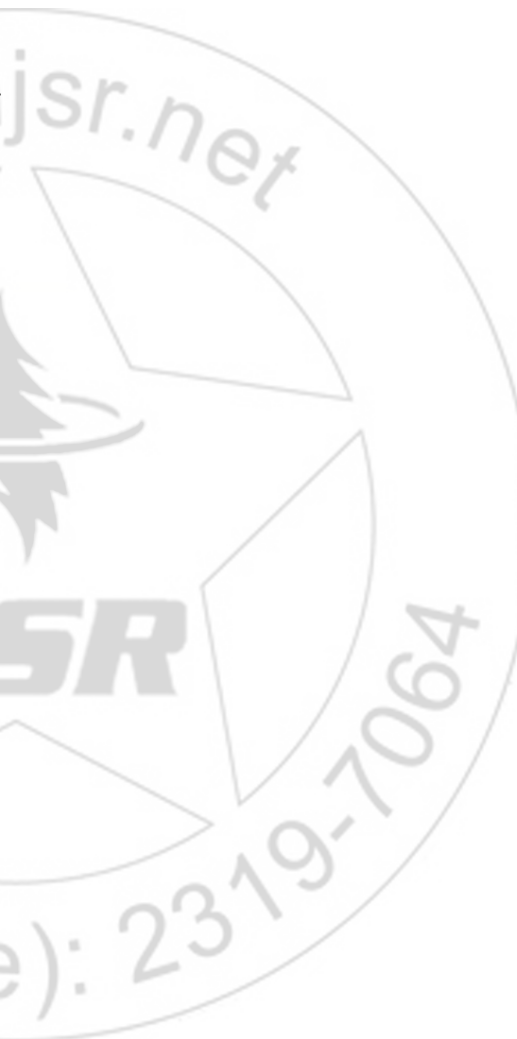

